\section{Myth, magic and the common solution}

\author{
Anthony W. Clare
}

Sherlock Holmes and the Case of Dr Freud. By Michael Shepherd. Tavistock: 1985. Pp.31. Pbk £2.95,\$5.95.

IN Nicholas Meyer's The Seven Per Cent Solution, Sherlock Holmes, suffering from a severe mental disorder with delusional ideas concerning the machinations of a harmless Professor Moriarty, meets and is treated by Sigmund Freud who is at the time a young physician in Vienna earning a reputation for himself treating the neuroses by an exciting new method of exploration. Cured by the treatment, Holmes joins forces with Freud and together they engage in a successful hunt for a villain who is attempting to precipitate a world war.

Michael Shepherd, Professor of Epidemiological Psychiatry at the Institute of Psychiatry in London, opens what is a deceptively temperate essay with this revisionist view of Conan Doyle's hero. The reason he does so is quite simply that he is about similar business with regard to the sage of Vienna and the founder of psychoanalysis. Sherlock Holmes made the external world coherent by solving mysteries using a method of procedure

AIVVERTISEMENT

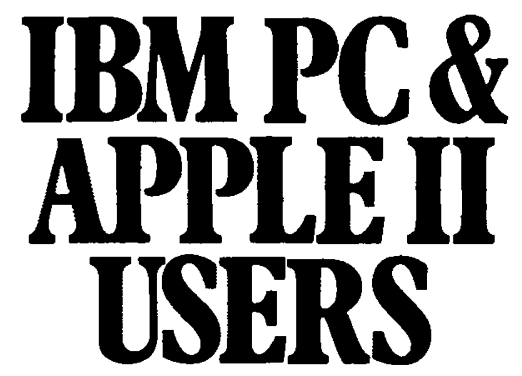

Dramatic advances are being made in scientific tools for personal computers. Jandel Scientific specializes in software and peripherals for

- Planimetry, digitizing

- Interactive Statistics

- Dynamic System Simulation

- Computer-generated lecture Slides

\section{- And more}

Call us and let our technical advisors help you find the product you need. Or write or call for our FREE catalog.

\section{JANDEL SCIENTIFIC}

2656 BRIDGEWAY

SAUSALITO, CA 94965

CALL TOLL-FREE 800-874-1888

IN CALIF. CALL 415-331-3022

Reader Service No.14 which, although appealingly labelled as deductive and logical, was in actual fact intuitive and illogical. However, so attractively human was it that it was and continues to be enormously popular and enjoyable in contrast to the numbing tedium of the real process of detection. Freud, likewise, appeared to make the world comprehensible by solving internal mysteries by a method which, Shepherd argues, was no less intuitive and illogical whatever the claims for scientific status made by Freud and his successors on its behalf. In precisely the sense that Holmes is a caricature of the real life detective, so Freud is a caricature of the psychiatrist.

However, there is more to the link between the fictional private eye from Baker Street and the actual therapeutic ear from the Berggasse. Both Holmes and Freud are the stuff of which heroes are made. Shepherd quotes Brigid Brophy and her view that the cause in which the modern detective employs his method and skill remains the same as that in which the Greek hero used his magic powers - "the deliverance of the population from a threat". In sociological terms, the detective story offers its readers a reassuringly comprehensible and predictable world in which those who try to upset the established order are always detected and punished. Freud's great case-histories read like stories in a Holmesian omnibus and a contemporary novelist, D. M. Thomas, has gone so far as to argue that in his clinical accounts Freud was often fictionalizing, as intent on getting "a good story, a well-shaped classical Greek story, as to get at the truth". Freud and Holmes, Shepherd suggests with more than a touch of mischief, are examples of Nietzsche's ubermensch, the new man, detached, quasi-omniscient, a contemporary hero of an ancient legend.

It is an effervescent, provocative, humorous yet profoundly serious argument, and Shepherd elegantly draws on the sympathetic effusions of many of the literary supporters of psychoanalysis to illuminate his view that psychoanalysis, wherever it ultimately belongs, appears more at home within the sphere of myth than of medicine. Others have had the same idea (for example an equivalent argument is mounted in Ernest Gellner's recently published The Psychoanalytic Movement), but few have made the case with such an economy of words and breadth of scholarship. To those who know Shepherd and his work, this lively appetizer will maddeningly remind them of the more substantial meal he could cook if the spirit but moved him. Disciples of Freud and psychoanalysis may well breathe a sigh of relief that to date it has failed to do so.

Anthony W. Clare is Professor of Psychological Medicine at St. Bartholomew's Hospital Medical College. West Smithfield, London ECIA $7 B E, U K$.

\section{The fitful gleam}

\author{
P.W. Hawkes
}

Statistical Optics. By Joseph W. Goodman. Wiley: 1985. Pp.550. £49.85, \$59.80.

FLICKERING, glistening, twinkling, shimmering: the literary vocabulary of optics should lead us to expect statistics to play a large part in the subject even if the scientific language is more sober. There are indeed branches of optics - coherence, speckle, some image restoration methods, image compression, some aspects of pattern recognition, weak signal detection which require a thorough knowledge of statistics, but the first books on probability with special reference to optics have appeared only very recently. The first, Probability, Statistical Optics, and Data Testing, written by B. R. Frieden and published by Springer-Verlag, appeared in 1983 and set a very high standard. Although Goodman's new text contains some material that is also to be found in Frieden, the two books are otherwise very different in coverage.

Statistical Optics opens with a brisk account of probability theory and random processes, written in the spirit of a revision aid. Individual chapters are then devoted to first-order statistics, the traditional study of temporal and spatial coherence in terms of second-order statistics, situations in which higher-order coherence arises, image formation with partially coherent light and the phase problem, propagation through random media and, finally, the detection of weak optical signals

The ratio of optics to statistics is uneven. The chapter on first-order properties is a successful attempt to inculcate statistical thinking habits into students of optics, through the study of thermal light and laser light. The following chapter, on coherence, follows the reasoning made familiar by such standard texts as Born and Wolf's Principles of Optics (Pergamon, 1980) and the same is true of most of the later chapter on effects due to partial coherence in imaging systems. The latter concludes with a very brief account of phase retrieval and a slightly longer section on speckle. In the case of phase retrieval, there is hardly any discussion of the extremely important problem of noise in the various reconstruction methods, which is a disappointing and surprising omission because this is an eminently statistical topic. The chapter on higher-order coherence (of which subject it is distinctly less easy to find an elementary account) is much more useful.

The two concluding chapters, on imaging through randomly inhomogeneous media and fundamental limits in photoelectric light detection, are genuine statistical optics, in which the interdependence between the two fields is shown clearly. Goodman leads us through the theory of 